\title{
The failure of China's Energy Development Strategy 2050 and its impact on carbon emissions
}

\author{
Jie Fan ${ }^{\mathrm{a}, \mathrm{b}}$, Qiang Wang ${ }^{\mathrm{c}}$, Wei Sun ${ }^{\mathrm{a}, \mathrm{b}, *}$ \\ ${ }^{a}$ Key Laboratory of Regional Sustainable Development Modeling, Chinese Academy of Sciences, Beijing 100101, China \\ ${ }^{\mathrm{b}}$ Institute of Geographic Sciences and Natural Resources Research, Chinese Academy of Sciences, Beijing 100101, China \\ ' College of Geographical Sciences, Fujian Normal University, Fuzhou 350007, China
}

\section{A R T I C L E I N F O}

\section{Article history:}

Received 18 May 2014

Received in revised form

3 April 2015

Accepted 23 April 2015

Available online 22 May 2015

\section{Keywords:}

Energy

Strategy

Carbon emissions

China

\begin{abstract}
A B S T R A C T
China is the world's largest energy consumer and emitter of carbon. China's energy development strategy is thus of great significance to the world's energy security and global carbon reduction target. In this study, the implementation of "China's Energy Development Strategy 2050" (EDS2050), which has been in operation since 1985, is investigated. This study analyzes the causes of the failure of EDS2050 and the impacts of that failure on carbon emissions. The results show the following: (1) EDS2050 basically failed in 2010, and the strategic planning values of primary energy consumption and production were underestimated compared with the actual values by $39 \%$ and $67 \%$, respectively. (2) Comparing the predicted values of basic parameters in EDS2050 with the actual values, in the production field, the main causes of failure were the underestimation of the economic growth rate and the proportion of non-agricultural industries, while in the living field, the main causes were the underestimation of urbanization and per capita energy consumption in rural areas. Further analyses of various provinces demonstrated that the major factors leading to EDS2050 failure include the economic growth rate, urbanization, population growth, and the growth in car ownership. (3) EDS2050 failure resulted in an increase in carbon emissions in 2010 of $583.50 \times 10^{6} \mathrm{tc}$, and increases of per capita carbon emissions reached 46.49-47.04\%; carbon emissions per unit of output demonstrated a reduction, which was as a result of technological progress. Improving energy efficiency, optimizing energy utilization, and promoting national energy conservation should be highly emphasized in China's future sustainable energy development strategy.
\end{abstract}

(c) 2015 Elsevier Ltd. All rights reserved.

\section{Contents}

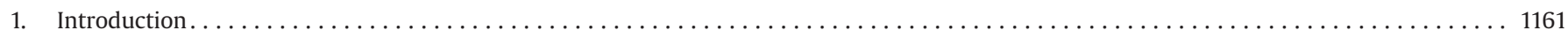

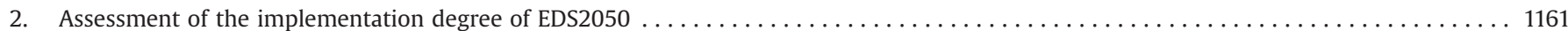

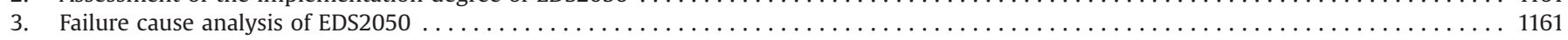

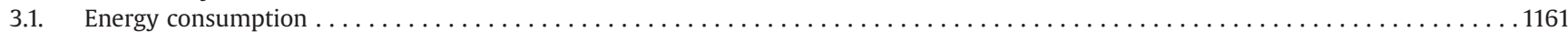

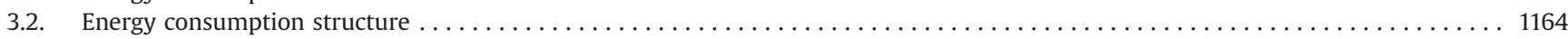

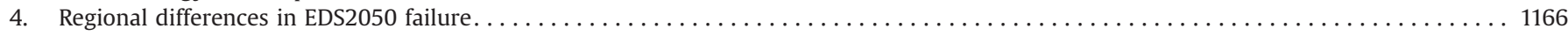

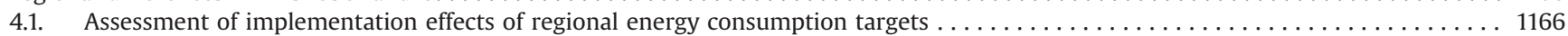

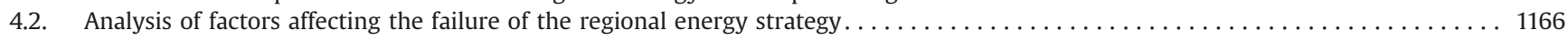

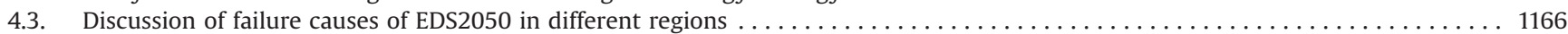

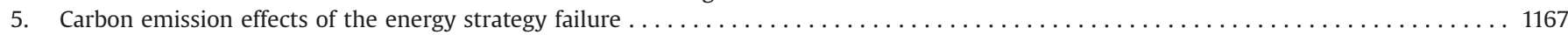

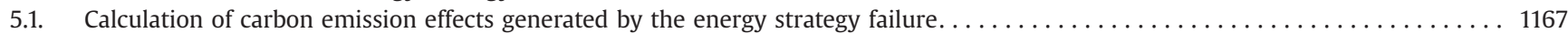

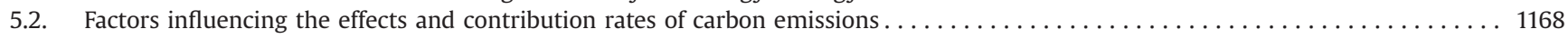

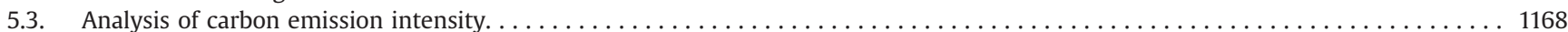

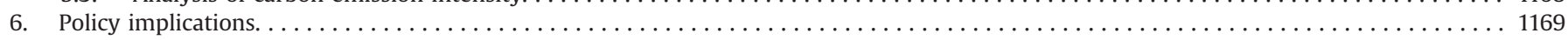

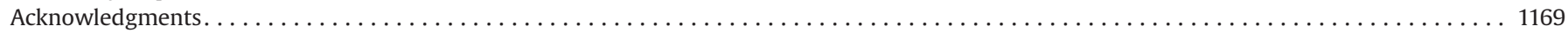

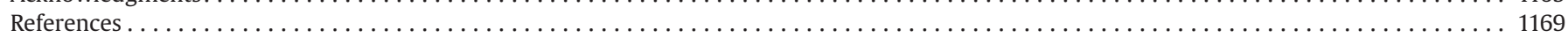

\footnotetext{
* Corresponding author. Tel.:+86 1064889284.

E-mail address: sunw@igsnrr.ac.cn (W. Sun).
} 


\section{Introduction}

China has become the world's largest energy consumer, with consumption increasing from $5.71 \times 10^{8}$ tce in 1978 to $32.49 \times$ $10^{8}$ tce in 2010. Its proportion of total global energy consumption rose from $6 \%$ to $20.3 \%$ in the same time. In addition, China has become the world's largest emitter of carbon, with carbon dioxide emissions increasing from $3.98 \times 10^{8} \mathrm{t}$ in 1978 to $20.95 \times 10^{8} \mathrm{t}$ in 2010 , and its proportion of the global total rose from $8.4 \%$ to $24.6 \%$. With its constantly increasing energy consumption in the future, China should further expand the intensity of energy development, which should have a significant impact on the outlook of global carbon emissions.

Energy development strategy (EDS) not only is an important research issue in academia, but it is also of great concern to governments [1-9]. For a long time, predicting and optimizing the scale and structure of the supply and demand of energy, promoting energy conservation and sustainable utilization, and maintaining energy security have been the focus of EDS and energy planning, which mainly concern influential factors such as population, gross domestic product (GDP), import and export amounts, urbanization, industrial structure, energy prices, registered vehicles and policies [10-12]. In order to achieve this, the following models have been used: linear regression, autoregressive integrated moving average, artificial neural networks, genetic algorithms, ant colony optimization, particle swarm optimization, grey model, and long-range energy alternatives planning system [13-20]. In recent years, research of EDS has gradually expanded to impacts on the environment, especially on carbon emissions and climate change [21-25]. EDS has therefore become a comprehensive research topic. However, it is still not see more that taking the scenario prediction, scheme optimization, implementation effect evaluation, and analysis of failure causes and consequences as the research focus.

Energy strategy has always been an important area of concern for the Chinese government regarding industrialization, and is an important field in the formulation of development plans and strategies [26]. In 1985, led by the Ministry of Energy, the Chinese government organized more than 300 staff in decision-making departments and research institutes to jointly prepare "China's Energy Development Strategy 2050" (referred to as EDS2050) ${ }^{1}$ within a period of 3 years, which marked the achievement of China's first development of a longterm strategy. Currently, this strategy has been implemented for more than 20 years, but through comprehensive assessment, the strategy has been shown to be basically ineffective. What are the reasons leading to the failure of EDS2050? Which reasons are inevitable? Which reasons can be avoided? If there is a strategy failure, to what extent does that failure lead to the production of increased effects on the scale and intensity of carbon emissions? These are the main issues that are discussed in this study, the results of which can provide a good reference for the development of China's energy development strategies and energy policies in the future.

The following approaches are used in this study. The predicted values of energy consumption and production developed by EDS2050 are compared with actual values to demonstrate whether or not failure exists, and if so, the extent of that failure. Then, the predicted values of key factors for EDS2050 are compared with actual values to analyze the major causes of strategic failure. The major causes leading to the failure of EDS2050 are combined to calculate their effects on carbon emissions. Next, the differences in the failure of EDS2050 in 30 Chinese provinces and municipalities are taken as an auxiliary method to demonstrate the contribution of major factors leading to the failure of EDS2050. The data in this study are mainly sourced from three data sets. The first is the data

\footnotetext{
${ }^{1}$ The author of this study was directly involved in the research formulation of “China's Energy Development Strategy in 2050".
}

set used during EDS2050 formulation, which includes published development strategy indicators and a basic database to measure and determine the impact factors of EDS2050. The second is population and economic development statistics, as well as energy statistics for China and various other regions over the past 30 years. The third is the carbon emission database established by the Chinese Academy of Sciences in recent years.

\section{Assessment of the implementation degree of EDS2050}

The major planning indicators of energy development determined by EDS2050 are compared with the actual energy production and consumption values in 2000 and 2010, and the actual value $(A)$, planning value $(P)$, and deviation $(r)$ are taken as indicators. The deviation between the planning value $P_{P}$ and actual value $A_{P}$ of energy production is expressed as a percentage of the difference between the planning value and actual value accounting for the planning value, i.e. $r_{P}=\left(A_{P}-P_{P}\right) * 100 / P_{P}$. The deviation between the planning value $P_{C}$ and the actual value $A_{C}$ of energy consumption is expressed as a percentage of the difference between the planning value and the actual value accounting for the planning value, i.e. $r_{C}=\left(A_{C}-P_{C}\right) * 100 / P_{C}$. The structural deviation in energy production (consumption) is expressed by the difference between the actual proportion of various energies accounting for the total energy $\left(A_{s}\right)$ and the planning proportion, i.e. $r_{s}=A_{s}-P_{s}$. In this study, $r$ defined in $[-5 \%, 5 \%]$ is considered as effective implementation of the planning indicators; $r$ greater than this deviation interval is considered as implementation failure.

As can be seen in Table 1, in the period 2000-2010, the growth rate of primary energy consumption was $8.36 \%$ per year, more than triple the global average, and 30 times the average of the Organisation for Economic Co-operation and Development (OECD). Due to this increase in energy consumption, there was a failure of implementation of multiple key factors in the EDS2050 implementation process between 1990 and 2010, during which time, the deviation of energy production reached its maximum. Moreover, the deviation increased over time, i.e. the deviation in 2010 was generally greater than that in 2000. The failure of EDS2050 in 2010 will be the focus of discussions in the following sections. The overestimation of the amount of oil and gas production is the item with maximum deviation in the energies classified.

Further analyzing the data for 2010 shown in Table 1, the following findings can be obtained. First, the proportion of the gap between energy consumption ( $\left.\mathrm{Con}_{2010}\right)$ and energy production $\left(\mathrm{PrO}_{2010}\right)$ in the same year, accounting for energy consumption $\left(m_{2010}\right)$, is taken as the dependence on net energy imports, i.e. $m_{2010}=\left(\mathrm{Con}_{2010}-\mathrm{Pro}_{2010}\right) / P_{2010}$; the planning value in 2010 was set at $24 \%$, while the actual value was only $9 \%$, so the proportion of imported energy was significantly higher in EDS2050. Second, if the term $n_{2010}=\left(A_{\mathrm{C} 2010}-P_{P 2010}\right) / P_{P 2010}$ represents the deviation $\left(n_{2010}\right)$ between the actual energy consumption $\left(A_{C 2010}\right)$ and energy planning production $\left(P_{P 2010}\right)$ in 2010 , then the maximum actual deviation of EDS2050 can be observed to be $161.81 \%$. This indicates that, in order to balance the predicted production and actual consumption in 2010, the gap reached the extremes of the deviations of various indicators in EDS2050. It can therefore be seen that EDS2050 was basically ineffective in 2010.

\section{Failure cause analysis of EDS2050}

\subsection{Energy consumption}

EDS2050 is taken as the basis for energy consumption planning, mainly through predicting key indicators of energy consumption for 
Table 1

Comparison between planning values and actual values in EDS2050.

Source: China's Energy Development Strategy in 2050, China Energy Statistical Yearbook in 2001 and 2011, http://data.worldbank.org.cn/.

\begin{tabular}{|c|c|c|c|c|c|c|c|c|c|c|}
\hline \multirow[t]{3}{*}{ Indexes } & \multicolumn{5}{|l|}{2000} & \multicolumn{5}{|l|}{2010} \\
\hline & \multirow[t]{2}{*}{$P_{2000}$} & \multicolumn{3}{|l|}{$A_{2000}$} & \multirow{2}{*}{$\begin{array}{l}r_{2000} \\
\text { China }\end{array}$} & \multirow[t]{2}{*}{$P_{2010}$} & \multicolumn{3}{|l|}{$A_{2010}$} & \multirow{2}{*}{$\begin{array}{l}r_{2010} \\
\text { China }\end{array}$} \\
\hline & & China & World & OECD & & & China & World & OECD & \\
\hline Primary energy consumption ( $10^{4}$ tce) & 146061 & 145531 & 1386919 & 807974 & -0.36 & 234000 & 324939 & 1774912 & 831109 & 38.86 \\
\hline Proportion of coal (\%) & 76 & 69.20 & 25.08 & 20.82 & -6.80 & 70.15 & 68 & 29.63 & 19.82 & -2.15 \\
\hline Proportion of oil (\%) & 15 & 22.20 & 38.36 & 40.86 & 7.20 & 17.10 & 19 & 33.56 & 37.96 & 1.9 \\
\hline Proportion of gas (\%) & 2.6 & 2.20 & 23.3 & 22.52 & -0.40 & 3.55 & 4.4 & 23.81 & 25.10 & 0.85 \\
\hline Proportion of hydropower and nuclear power (\%) & 6.4 & 6.40 & 13.26 & 15.81 & 0.00 & 9.20 & 8.6 & 13.00 & 17.12 & -0.6 \\
\hline Primary energy production $\left(10^{4}\right.$ tce $)$ & 134410 & 135048 & 1200106 & 457816 & 0.47 & 177800 & 296916 & 1533104 & 463486 & 66.99 \\
\hline Proportion of coal (\%) & 74.4 & 73.21 & 22.78 & 26.08 & -1.19 & 71.09 & 76.56 & 27.66 & 25.92 & 5.47 \\
\hline Proportion of oil (\%) & 16.44 & 17.24 & 36.06 & 26.26 & 0.80 & 13.27 & 9.77 & 31.03 & 22.10 & -3.5 \\
\hline Proportion of gas (\%) & 2.98 & 2.68 & 21.67 & 25.41 & -0.30 & 7.48 & 4.25 & 22.44 & 26.90 & -3.23 \\
\hline Proportion of hydropower and nuclear power (\%) & 6.18 & 6.87 & 19.49 & 22.24 & 0.69 & 8.16 & 9.42 & 18.87 & 25.08 & 1.26 \\
\hline
\end{tabular}

Note: The figures for World and OECD have been converted from oil equivalent to coal equivalent.

Table 2

Deviation between predicted parameters and actual values of primary energy consumption indicators in EDS2050.

Source: China's Energy Development Strategy in 2050, China Statistical Yearbook in 2001 and 2011, http://data.worldbank.org.cn/.

\begin{tabular}{|c|c|c|c|c|c|c|c|c|c|c|}
\hline \multirow[t]{3}{*}{ Indexes } & \multicolumn{5}{|l|}{2000} & \multicolumn{5}{|l|}{2010} \\
\hline & \multirow[t]{2}{*}{$P_{2000}$} & \multicolumn{3}{|l|}{$A_{2000}$} & \multirow{2}{*}{$\begin{array}{l}A_{2000}-P_{2000} \\
\text { China }\end{array}$} & \multirow[t]{2}{*}{$P_{2010}$} & \multicolumn{3}{|l|}{$A_{2010}$} & \multirow{2}{*}{$\begin{array}{l}A_{2010}-P_{2010} \\
\text { China }\end{array}$} \\
\hline & & China & World & OECD & & & China & World & OECD & \\
\hline Population ( $10^{8}$ persons) & 12.94 & 12.67 & 61.02 & 11.56 & -0.27 & 14.23 & 13.41 & 68.84 & 12.40 & -0.82 \\
\hline Urban population ( $10^{8}$ persons) & 4.53 & 4.59 & 28.40 & 8.75 & 0.06 & 6.45 & 6.70 & 35.48 & 9.80 & 0.25 \\
\hline GDP $\left(10^{8} \mathrm{RMB}\right.$, at constant prices of 1990$)$ & 38846 & 49742 & 1381433 & 1124668 & 10896 & 85287 & 144454 & 2706787 & 1837458 & 59167.70 \\
\hline GDP growth rate (\%) & 8.19 & 8.60 & 4.27 & 3.96 & 0.41 & 8.20 & 10.68 & 4.08 & 2.92 & 2.60 \\
\hline Proportion of primary industries (\%) & 23.00 & 15.10 & 4.00 & 1.95 & -7.90 & 18.00 & 10.10 & 3.04 & 1.53 & -7.90 \\
\hline Proportion of secondary industries (\%) & 44.10 & 45.90 & 29.24 & 27.20 & 1.80 & 43.50 & 46.80 & 26.97 & 24.37 & 3.30 \\
\hline Proportion of tertiary industries (\%) & 32.90 & 39.00 & 66.76 & 70.85 & 6.10 & 38.50 & 43.10 & 69.99 & 74.10 & 4.60 \\
\hline Energy consumption per unit of output (tce $/ 10^{4} \mathrm{RMB}$ ) & 3.76 & 2.93 & 1.81 & 1.62 & -0.83 & 2.76 & 2.37 & 1.62 & 1.42 & -0.40 \\
\hline
\end{tabular}

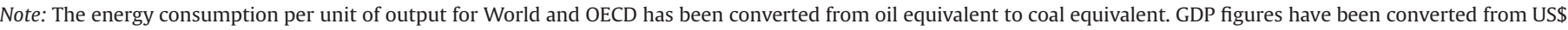
to RMB.

each energy consumption unit, including two types of core indicators, i.e. the development scale and energy consumption intensity of each energy consumption unit, in order to derive the planning value of the total social energy consumption. Therefore, interpretation of the reasons for planning failure rests on analyzing whether or not the predicted deviation exists in the main parameters affecting the predicted values of these two types of core indicators, and why the predicted deviation exists. Of course, the intensity of energy consumption here is not only a predictor, but also an important planning indicator in EDS2050, because it comprehensively reflects the energy-saving targets of society as a whole, and those of various sectors and regions.

In accordance with the comparison between the predicted parameter values of EDS2050 in 2010 and the actual values in 2010, there are three terms that are overestimated (see Table 2): total population, proportion of primary industries, and energy consumption per unit of output. The underestimated terms include the level of urbanization, GDP growth rate, and the proportion of non-agricultural industries (including secondary and tertiary industries). In the case of various parameters affecting the deviations between the actual energy consumption values and planning values, the parameters with decreasing effects include total population and energy consumption per unit of output, while all other parameters have increasing effects. For this reason, the discussion is carried out through classification.

In the production field, a consensus has been formed regarding GDP growth rate between the government and academics in the formulation period of EDS2050. In the first decade of the 21st century, the GDP growth rate of $8 \%$ was a success, as it was much higher than the global average of around 6\%, and was more than triple the growth rate of OECD member countries. In fact, the Chinese economic development stimulus led to a GDP growth rate rising to $10 \%$. In addition, the actual value of the GDP was higher than the predicted value of the energy strategy by 69\% in 2010 . According to these data, under the premise that energy consumption per unit of output remained unchanged ( $\left.2.76 \mathrm{tce} / 10^{4} \mathrm{RMB}\right)$, the theoretically increased energy consumption was $16.33 \times 10^{8}$ tce.

In addition to the underestimation of GDP, the prediction deviation of the Chinese economic structure has also become an important aspect leading to the failure of EDS2050. According to EDS2050, it may be judged that the Chinese industrialization processes, or more specifically, the non-agricultural industries cannot continue to undergo the significant changes they went through in the first 10 years of the Reform and Opening Up Policy. The proportion of nonagricultural industries increased from $69.80 \%$ in 1980 to $72.90 \%$ in 1990 , with an annual average growth of $0.31 \%$. Therefore, the predicted value of the proportion of non-agricultural industries was $82 \%$ in 2010 , with a 20 -year average growth of $0.46 \%$. In fact, an important force supporting the Chinese 30-year sustained rapid economic development was the rapid development of nonagricultural industries. The proportion of non-agricultural industries reached $90 \%$ in 2010 , less than both the global average and that of OECD member countries by $6 \%$, at an annual average growth rate of $0.67 \%$, which is equivalent to that of the first 10 years of the Reform and Opening Up Policy. The rise in the proportion of non-agricultural industries, particularly the constant improvement in the proportion 
of secondary industries, significantly improves the level of energy consumption per unit of output from industrial structures. However, because industrial energy efficiency was taken as the core task of EDS2050, in particular, the transition of the development pattern in the 21st century has been to promote energy conservation, and the energy consumption per unit output has deceased by $19 \%$, from $2.93 \mathrm{tce} / 10^{4} \mathrm{RMB}$ in 2000 to $2.37 \mathrm{tce} / 10^{4} \mathrm{RMB}$ in 2010 . Although the energy consumption per unit output fell rapidly, China still has a long way to go compared with the levels of OECD member countries. The energy consumption per unit of output is beyond the energy savings target proposed by EDS2050 (see Table 3), and this energy efficiency effect is greater than the industrial structure effect. In brief, the actual energy consumption of the Chinese production sector in 2010 $\left(30.75 \times 10^{8}\right.$ tce $)$ was greater than the planning value $(20.15 \times$ $10^{8}$ tce) by $10.60 \times 10^{8}$ tce, accounting for $45.29 \%$ of the total energy consumption planning amount $\left(23.40 \times 10^{8}\right.$ tce $)$.

In the living field, it was predicted that China would relax its population and family planning policies after 2000 in EDS2050, and the Chinese total population would then grow rapidly. In fact, the control of population growth has always been an important national policy. The total population did not grow according to the rate determined by the predicted parameter values of EDS2050; it increased by only 82 million. In accordance with per capita household energy consumption standards determined by EDS2050 (254 kgce/person, see Table 4), the total population showed a lower increase in energy consumption of $20.83 \times 10^{6}$ tce. In addition, the underestimation of urbanization level, particularly the underestimation of the rural household energy consumption level, significantly affected the underestimation of Chinese household energy consumption. It was considered in EDS2050 that the maximum value of the Chinese urbanization rate was $45 \%$ in 2010, but in fact, in the 21st century, China has always taken the acceleration of urbanization as an important method to achieve modernization of the country. In the past three consecutive 5-year plans, urbanization has been raised to the level of a national major strategic task, and the urbanization rate reached $50 \%$ in 2010 . In accordance with the standard of urban per capita household energy consumption determined by EDS2050 (387 kgce/person), this measure can increase the urban per capita household energy consumption by $96.75 \times 10^{6}$ tce.

In addition, through comparing the predicted parameter values and actual values of urban per capita energy consumption, it can be seen that the urban per capita energy consumption has decreased significantly. This is not due to household energy savings, but rather is due to the insignificant improvements in average urban living quality during the rapid urbanization processes. The actual quality of living levels of more than 200 million rural migrant workers included in the total urban population is very low. The survey shows that the household energy consumption levels are half those of the urban per capita energy consumption levels, and are basically approaching the rural average energy consumption standard. The prediction of rural per capita household energy consumption was based on the view that rural areas would be undeveloped for a long time, and that urbanization was the only way to improve living standards. Therefore, the rural per capita household energy consumption was $138 \mathrm{kgce} /$ person in 2010, an increase of only 13\% compared to the 2010 standard determined by EDS2050. In fact, new rural constructions and improvement of farmers' income levels have led to a rapid increase in the standard of household energy consumption. In 2000, among every 100 peasant households, average ownership was 1 air conditioner, 12 refrigerators, 22 motorcycles, and 1 computer; in 2010, this rose to 16 air conditioners, 45 refrigerators, 60 motorcycles, and 10 computers. Although the total farmer population decreased by 137 million from 2000 to 2010, the actual per capita household energy consumption increased by $168 \%$ during this period, reaching 204 kgce/person, thus significantly narrowing the gap between urban and rural household energy consumption. In accordance with the rural population of 731 million, the predicted value of rural household energy consumption in EDS2050 was lower than the actual value by $48.25 \times 10^{6}$ tce. In summary, due to the combination of the underestimation effects of the urbanization level and the urban per capita household energy consumption standard, the actual value of energy consumption in the Chinese living field $\left(3.66 \times 10^{8}\right.$ tce $)$ differs little from the planning value $\left(3.61 \times 10^{8}\right.$ tce), increasing by only $4.20 \times 10^{6}$ tce, and accounting for $0.18 \%$ of the planned amount of energy consumption $\left(23.40 \times 10^{8}\right.$ tce $)$.

Table 3

Comparison between the predicted values of energy consumption per unit of output for three industries and the actual values in EDS2050.

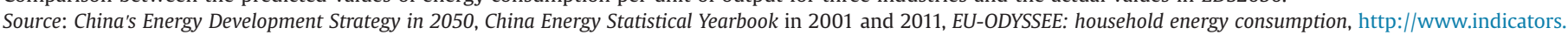
odyssee-mure.eu/online-indicators.html.

\begin{tabular}{|c|c|c|c|c|c|c|c|c|}
\hline \multirow[t]{3}{*}{ Indexes } & \multicolumn{4}{|l|}{2000} & \multicolumn{4}{|l|}{2010} \\
\hline & \multirow[t]{2}{*}{$P_{2000}$} & \multicolumn{2}{|l|}{$A_{2000}$} & \multirow{2}{*}{$\begin{array}{l}A_{2000}-P_{2000} \\
\text { China }\end{array}$} & \multirow[t]{2}{*}{$P_{2010}$} & \multicolumn{2}{|l|}{$A_{2010}$} & \multirow{2}{*}{$\begin{array}{l}A_{2010}-P_{2010} \\
\text { China }\end{array}$} \\
\hline & & China & OECD & & & China & OECD & \\
\hline Primary industries (tce $/ 10^{4} \mathrm{RMB}$ ) & 0.84 & 0.52 & - & -0.32 & 0.76 & 0.47 & - & -0.29 \\
\hline Secondary industries (tce $/ 10^{4} \mathrm{RMB}$ ) & 5.64 & 4.67 & 0.36 & -0.97 & 4.18 & 3.72 & 0.30 & -0.46 \\
\hline Tertiary industries (tce $/ 10^{4} \mathrm{RMB}$ ) & 1.33 & 1.04 & 0.06 & -0.29 & 1.06 & 0.79 & 0.06 & -0.27 \\
\hline
\end{tabular}

Table 4

Comparison between the predicted values of household energy consumption and the actual values in EDS2050. Source: China's Energy Development Strategy in 2050, China Energy Statistical Yearbook in 2001 and 2011.

\begin{tabular}{|c|c|c|c|c|c|c|}
\hline \multirow[t]{2}{*}{ Indexes } & \multicolumn{3}{|l|}{2000} & \multicolumn{3}{|l|}{2010} \\
\hline & $P_{2000}$ & $A_{2000}$ & $A_{2000}-P_{2000}$ & $P_{2010}$ & $A_{2010}$ & $A_{2010}-P_{2010}$ \\
\hline Per capita energy consumption (kgce/person) & 208.00 & 123.19 & -84.81 & 254.00 & 272.66 & 18.66 \\
\hline Urban population ( $10^{8}$ persons) & 4.53 & 4.59 & 0.06 & 6.45 & 6.70 & 0.25 \\
\hline Rural population ( $10^{8}$ persons) & 8.41 & 8.08 & -0.33 & 7.31 & 6.71 & -0.60 \\
\hline Urban per capita household energy consumption (kgce/person) & 368.00 & 210.00 & -158.00 & 387.00 & 315.00 & -72.00 \\
\hline Rural per capita household energy consumption (kgce/person) & 122.00 & 76.00 & -46.00 & 138.00 & 204.00 & 66.00 \\
\hline
\end{tabular}


It can be seen that the failure of EDS2050 was first exhibited in the production field, and the underestimations of the economic development rate and industrialization were the core reasons. In the living field, the underestimations of urbanization and rural per capita energy consumption were the main reasons. Controlling population growth and the energy saving in the production field have provided outstanding contributions to slowing the rapid growth in energy consumption. In addition, the long-term stagnation of urban household energy consumption reflects the fact that the quality of Chinese urbanization is relatively low.

\subsection{Energy consumption structure}

As viewed from the perspective of energy consumption (see Table 1), the proportion of coal use in the actual energy consumption decreased by $6.8 \%$ compared with the planning value in 2000 , and that of oil rose by $7.20 \%$ over the planning value. Although both deviations showed substantial narrowing until 2010, the problems of overestimation of the proportion of coal use and underestimation of the proportion of oil use still exist. The proportion of coal use was overestimated by $2.5 \%$, while that of oil use was underestimated by $1.9 \%$. The main reasons are as follows.

As it is affected by natural resources, coal has always occupied a dominant position in the Chinese primary energy consumption structure. The proportion of coal in primary energy consumption was maintained at approximately $70 \%$ in both 2000 and 2010. On one hand, it was not predicted in EDS2050 that coal product prices would show more substantial growth over the past 15 years, with an average annual increase rate of up to $10.30 \%$, forcing some energy-consuming companies to choose non-coal energy, and thus causing a decline in the proportion of coal use in the primary energy consumption structure. On the other hand, large-scale oil imports were not predicted in EDS2050 either. The proportion of imported oil consumption in the energy consumption structure was increased to substantially compensate for the reduction in the proportion of coal consumption.

Through analyzing the changes in the energy consumption structures of sectors, the industry with the largest energy consumption is shown to retain a stable situation. Over a period of 20 years, the energy consumption of the industrial sector increased from $6.76 \times 10^{8}$ tce in 1990 to $23.11 \times 10^{8}$ tce in 2010 , and its proportion of the total energy consumption of society as a whole remained at approximately 70\% in 2010 (see Fig. 1). Due to the rapid growth of metallurgy, electrical power, building materials, and other industries, the proportion of coal consumption in the industrial sector increased from $65.55 \%$ in 1990 to $82.63 \%$ in 2010 (see Fig. 2), revealing that Chinese energy consumption still shows a high dependence on coal. In contrast, the proportions of coal consumption in other energy-consuming sectors have shown varying degrees of decline. In the transportation, warehousing, postal, and telecommunication sectors, coal consumption increased from $45.41 \times 10^{6}$ tce in 1990 to $260.68 \times 10^{6}$ tce in 2010 , and its proportion of the total energy consumption rose from $4.60 \%$ in 1990 to

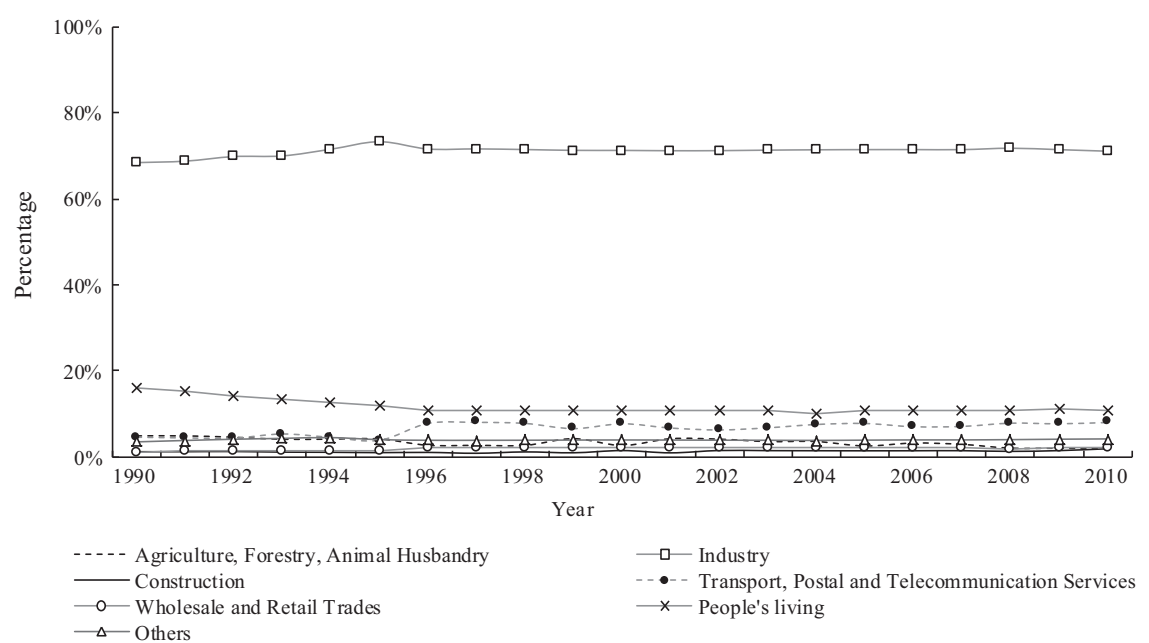

Fig. 1. Changes in the proportion of primary energy consumption of various sectors in total social energy consumption during $1990-2010$.

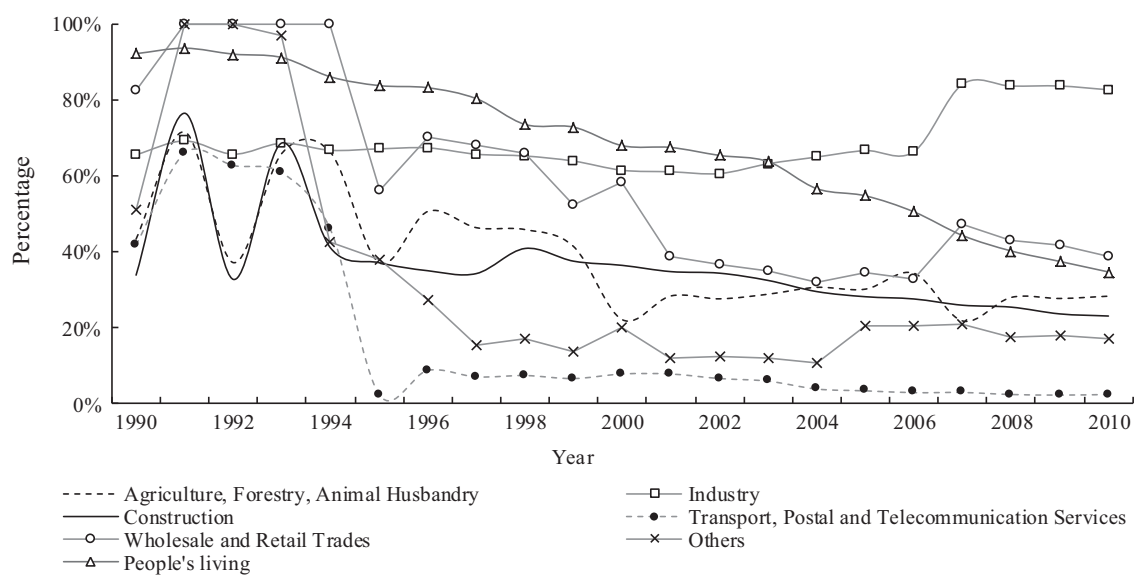

Fig. 2. Changes in the proportion of coal consumption of various sectors in total primary energy consumption during $1990-2010$. 
$8.02 \%$ in 2010 . It has therefore become the sector with the fastestgrowing energy consumption and the third largest energyconsuming sector in the national economy, of which the energy consumption structure is gradually shifting toward oil products. The proportion of oil consumption showed annual average growth rates of $3.40 \%$ and $0.62 \%$ in $1990-2000$ and $2000-2010$, respectively

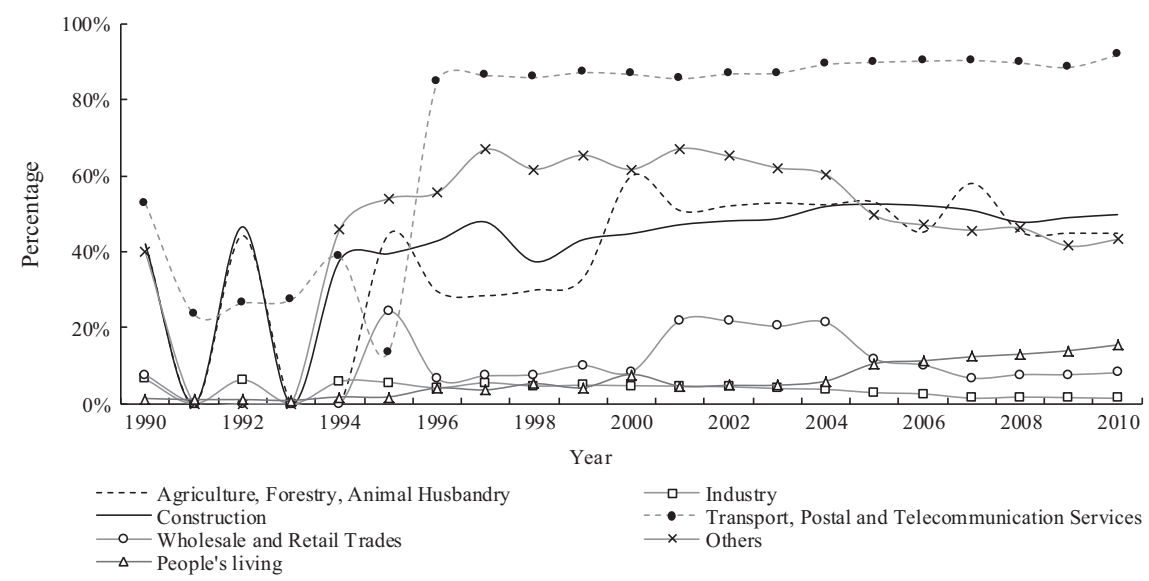

Fig. 3. Changes in the proportion of oil consumption of various sectors in total primary energy consumption during 1990-2010.



Fig. 4. Performance effect assessment chart of regional primary energy consumption in 2010. 
(see Fig. 3). It can be seen that the transportation industry presents a growing trend in oil consumption proportion due to the development of logistics, promoting diversified development of energy consumption types throughout Chinese society.

\section{Regional differences in EDS2050 failure}

There are significant differences among Chinese provinces in terms of resources, environment, population, economy, and other aspects. By analyzing the implementation effects of primary energy consumption indicators in EDS2050, the discussion of the causes of failure of EDS2050 may be deepened. In this study, the deviation $\left(r_{C}\right)$ between the actual value of provincial primary energy consumption $\left(A_{C}\right)$ and the planning value $\left(P_{C}\right)$ in 2010 is taken as the measure indicator. The natural breakpoint grading method on the ArcGIS technology platform is used for type classification of 30 provinces in mainland China (with no data for Tibet, Taiwan, Hong Kong, and Macao). In 2010, with the exception that the primary energy consumption of Jilin was overestimated $\left(r_{C}=-9.54 \%\right)$, the figures for the remaining 29 provinces were all underestimated (see Fig. 4). According to the degree of underestimation, these provinces were divided into five grades: mildly underestimated, generally underestimated, relatively severely underestimated, severely underestimated, and substantially underestimated. To facilitate the study, Jilin was also classified as a mildly underestimated area.

\subsection{Assessment of implementation effects of regional energy consumption targets}

It can be seen from Fig. 4 that the substantially underestimated and relatively severely underestimated areas of China are concentrated in the eastern coastal areas and western transition zones. The generally underestimated and mildly underestimated areas are distributed with distinct regional characteristics, and are mainly concentrated in the northeast and northwest regions. Only the severely underestimated areas are scattered and interspersed throughout the underdeveloped central and western regions, as well as the regions that have undergone large economic development efforts in recent years. Due to the changes in China's regional economic development pattern over the past 20 years, a large prediction deviation exists in the estimation of whether the economy continues to grow rapidly in the eastern coastal areas, as well as whether the western development policies can have a significant effect on conditional regions, thus causing the serious regional failure of EDS2050. The major failure areas refer to the regions with actual energy consumption of more than 0.9 times over the planning amount (including relatively severely underestimated areas, severely underestimated areas, and substantially underestimated areas), of which the proportions of population and economy accounted for $58.93 \%$ and $61.92 \%$, respectively, of the national total in 2010.

\subsection{Analysis of factors affecting the failure of the regional energy strategy}

According to the above analysis of the failure causes of EDS2050, economic output $\left(G D P_{t}\right)$, population $\left(P_{0} p_{t}\right)$, non-agricultural industrial structure (Non_Agr $r_{t}$ ), level of urbanization $\left(U r b_{t}\right)$, car ownership $\left(\mathrm{Car}_{t}\right)$, peasant income ( $\left.\mathrm{Per}_{-} \mathrm{Cap}_{t}\right)$, and energy consumption intensity $\left(E I_{t}\right)$ are selected as the influential factors to create the following econometric model. A stepwise regression method is used to analyze the energy consumption of 30 provinces over the past 20 years and its influential factors.

$E C_{t}=f\left(G D P_{t}\right.$, Pop $_{t}$, Non_Agr $_{t}, U r b_{t}$, Car $_{t}$, Per_cap $\left._{t}, E I_{t}\right)$
Table 5

Dominant factors influencing the underestimation of regional energy consumption and their contribution rates.

\begin{tabular}{lll}
\hline Grades & Dominant factors & $\begin{array}{l}\text { Contribution rates } \\
(\%)\end{array}$ \\
\hline Substantially underestimated area & $\begin{array}{l}\text { Economic growth } \\
\text { Population growth }\end{array}$ & 79 \\
& 21 \\
Severely underestimated area & Urbanization & 66 \\
& Growth of car & 34 \\
Relatively severely & ownership & \\
underestimated area & Economic growth & 81 \\
Generally underestimated area & Urbanization & 19 \\
& Economic growth & 74 \\
Mildly underestimated area & Urbanization & 26 \\
& Growth of car & 98 \\
& ownership & \\
\hline
\end{tabular}

$E C_{t}$ is the total energy consumption in year $t$, units: $10^{4}$ tce; $G D P_{t}$ is the total economic output in year $t$, units: $10^{8} \mathrm{RMB}$; $P o p_{t}$ is the regional population in year $t$, units: $10^{4}$ persons; Non_Agr $r_{t}$ is the proportion of non-agricultural industries in year $t$, units: \%; $U r b_{t}$ is the population urbanization level in year $t$, units: \%; $\mathrm{Car}_{t}$ is the car ownership per 100 households in year $t$, units: car; Per_cap is the rural per capita income in year $t$, units: $R M B /$ person; $E I_{t}$ is the intensity of energy consumption in year $t$, units: tce $/ 10^{4} \mathrm{RMB}$.

In this study, the stepwise regression model is used to screen the influential factors of the EDS2050 failure in different regions and provide the degree of importance of various factors, in order to quantitatively reveal the causes of EDS2050 failure. In the stepwise regression model, under the premise of avoiding spurious regression, all independent variables with significant effects on dependent variables are contained in the regression equation to remove the independent variables with insignificant effects on dependent variables, and the contribution rates of the various affecting factors are quantitatively expressed [27]. The calculated results are shown in Table 5.

\subsection{Discussion of failure causes of EDS2050 in different regions}

Beijing, Tianjin, and the old industrial bases of the northeast, including Heilongjiang, Jilin, and Liaoning, are the major coverage areas with regional revitalization policies. 20 years ago, these areas were the locations of the best industrial and urbanization bases in China. EDS2050 follows this trend to predict that these regions will continue to be at the forefront of population and economic growth, as well as for the industrialization and urbanization processes. Therefore, the deviation between the predicted value and the actual value is the smallest in these regions, where mildly underestimated areas and generally underestimated areas are concentrated. In these regions, GDP growth is the main cause of increase of energy consumption, as documented by many studies [11,28,29].

The eastern regions of rapid industrialization and urbanization include Hebei, Shandong, Jiangsu, Shanghai, Zhejiang, Fujian, and Guangdong, where the substantially underestimated and relatively severely underestimated areas are mainly distributed, and which are also the most significantly affected areas reflecting the serious failure of EDS2050. These regions benefit from the Reform and Opening Up Policy, which achieved rapid growth in 1978-1990. EDS2050 predicts that it will be difficult for the high growth rates to continue, especially given that the predicted value is roughly equivalent to the national average level in 2000-2010, i.e. the average GDP growth rate will be $7.5 \%$, and the level of urbanization will reach $58 \%$. In fact, over the past 20 years, the regional economy and level of urbanization have both maintained high growth rates. In 2000-2010, the average GDP growth rate and level of urbanization were $13.7 \%$ and $63.5 \%$, respectively. These are substantially 


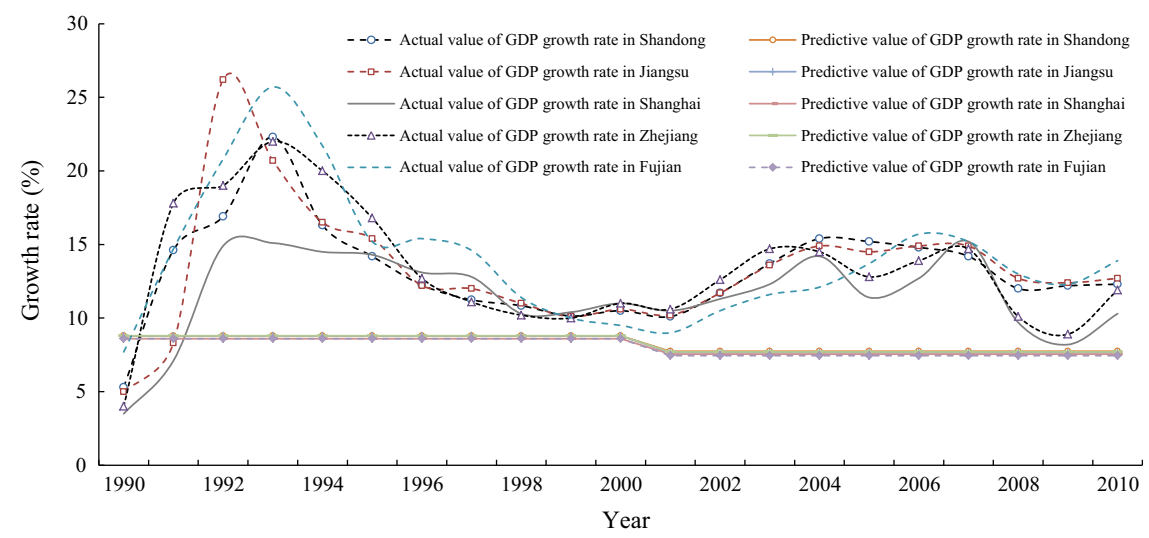

Fig. 5. Comparison between the predicted values of EDS2050 and the actual values of GDP growth rate in major eastern provinces.

Table 6

Changes in major indicators of various areas during 1990-2010.

Source: China Statistical Yearbook 1991-2011.

\begin{tabular}{|c|c|c|c|c|}
\hline Regions & $\begin{array}{l}\text { Economic growth rate } \\
(\%)\end{array}$ & $\begin{array}{l}\text { Population growth rate } \\
\text { (\%) }\end{array}$ & $\begin{array}{l}\text { Growth rate of car ownership } \\
(\%)\end{array}$ & $\begin{array}{l}\text { Growth of urbanization } \\
(\%)\end{array}$ \\
\hline Beijing, Tianjin, and the northeast old industrial base & 16.21 & 0.91 & 15.00 & 0.70 \\
\hline $\begin{array}{l}\text { Eastern rapid industrialization and urbanization } \\
\text { regions }\end{array}$ & 17.96 & 1.25 & 18.57 & 1.59 \\
\hline \multicolumn{5}{|l|}{ Central and western China } \\
\hline Severely underestimated area & 17.19 & 0.33 & 16.24 & 1.01 \\
\hline Relatively severely underestimated area & 16.16 & 0.50 & 20.91 & 1.25 \\
\hline Mildly underestimated area & 16.49 & 0.54 & 15.18 & 0.91 \\
\hline China & 16.58 & 0.80 & 16.64 & 1.18 \\
\hline
\end{tabular}

underestimated by EDS2050 (see Fig. 5). Therefore, our results yield evidence that the long-term industrialization and urbanization causes increases of energy consumption in eastern regions of China. Similar findings have been proved by other studies [12,30].

Severely underestimated, relatively severely underestimated, and generally underestimated areas are distributed throughout central and western China, which is the coverage area of two Chinese regional policies (see Table 6): western development and central rise. The implementation of regional policies displays different effects in different provinces. For example, EDS2050 has larger underestimated deviations in the provinces with high economic growth, rapid urbanization, slow population growth, and rapid growth in car ownership. Among these provinces, Chongqing, Guangxi, Anhui, Inner Mongolia, and Qinghai have had the highest economic growth rates in central and western China during recent years, and these areas are severely underestimated by EDS2050; meanwhile, Ningxia, Shaanxi, Sichuan, and Yunnan are at the forefront of the urbanization process, in which the underestimation deviation of EDS2050 is relatively significant.

In summary, the dominant factors affecting EDS2050 failure in China, in order, are: economic growth, urbanization, population scale, and car ownership.

\section{Carbon emission effects of the energy strategy failure}

\subsection{Calculation of carbon emission effects generated by the energy strategy failure}

Energy consumption scale and structure and utilization levels have significant impacts on carbon emissions. In this study, the carbon emission effects generated by the energy strategy failure are analyzed based on the changes in total carbon emissions and
Table 7

Changes in carbon emissions caused by EDS2050 failure (units: $10^{6}$ tc). Source: China's Energy Development Strategy in 2050, China Energy Statistical Yearbook in 2001 and 2011, National Development and Reform Commission of China, Department of Energy (USA), Oak Ridge National Laboratory (USA).

\begin{tabular}{llllr}
\hline Year & Source & \multicolumn{1}{l}{$C_{p}$} & \multicolumn{1}{c}{$C_{f}$} & \multicolumn{1}{c}{$C_{f}-C_{p}$} \\
\hline \multirow{2}{*}{2000} & IPCC & 986.56 & 964.83 & -21.73 \\
& NDRC & 937.28 & 931.74 & -5.54 \\
& DEUS & 887.22 & 873.85 & -13.37 \\
& ORNL & 931.14 & 927.03 & -4.11 \\
\multirow{2}{*}{2010} & IPCC & 1512.42 & 2095.92 & 583.50 \\
& NDRC & 1461.08 & 2023.73 & 562.65 \\
& DEUS & 1377.25 & 1901.85 & 524.61 \\
& ORNL & 1451.32 & 2009.83 & 558.51 \\
\hline
\end{tabular}

carbon emission intensity. Referring to the calculation equation of the carbon emission guidelines released by the Intergovernmental Panel on Climate Change (IPCC) in 2006 [31], and the carbon emission coefficients from the IPCC, National Development and Reform Commission of China, Department of Energy (USA), and Oak Ridge National Laboratory (USA), the difference in carbon emissions $\left(C_{f}-C_{p}\right)$ is calculated according to the actual value $\left(C_{f}\right)$ and the predicted value $\left(C_{p}\right)$ in 2010. The effect of the EDS2050 failure on the carbon emission increase is $583.50 \times 10^{6}$ tc in 2010 (see Table 7). As can be observed from the carbon emission intensity, the carbon emissions per unit of energy consumption and carbon emissions per unit of output in 2010 caused by EDS2050 failure decreased by $0.15-0.68 \%$ and $18.16-18.45 \%$, respectively, while the per capita carbon emissions showed an increased effect, rising by $46.49-47.04 \%$ (see Table 8). From the results, there are indeed impacts on carbon emissions, and the 
influence on the per capita carbon emissions is the highest. However, the basic conclusions are not radically changed.

\subsection{Factors influencing the effects and contribution rates of carbon emissions}

In order to quantitatively analyze the effects of various factors on carbon emissions, the Kaya Identity is combined with the Logarithmic Mean Divisia Index (LMDI) for no residual decomposition on carbon emissions [32,33]:

$\mathrm{CO}_{2}=\mathrm{POP} \times(\mathrm{GDP} / \mathrm{POP}) \times(\mathrm{E} / \mathrm{GDP}) \times\left(\mathrm{CO}_{2} / \mathrm{E}\right)$

where $\mathrm{CO}_{2}, \mathrm{POP}, \mathrm{GDP}$, and $\mathrm{E}$ respectively represent carbon dioxide emissions, total population, gross domestic product, and total primary energy consumption. It can be seen from Eq. (2) that carbon dioxide emissions are dependent on total population, per capita GDP, energy consumption intensity, and energy structural intensity.

The difference between actual carbon emissions and predicted carbon emissions is known as the total effect $\Delta C$, which consists of four parts: the population size effect of the total population growth $\left(\Delta C_{P}\right)$, the economic development effect of the per capita income change $\left(\Delta C_{P G}\right)$, the intensity effect caused by the energy consumption intensity $\left(\Delta C_{t}\right)$, and the structure effect of the energy consumption structural adjustment $\left(\Delta C_{s}\right)$. The LMDI method is applied to the decomposition analysis on the factors affecting carbon emissions. The results show that the economic development effect

Table 8

Changes in carbon emission intensity caused by EDS2050 failure. Source: China's Energy Development Strategy in 2050, China Energy Statistical Yearbook in 2001 and 2011, National Development and Reform Commission of China, Department of Energy (USA), Oak Ridge National Laboratory (USA).

\begin{tabular}{|c|c|c|c|c|c|c|}
\hline \multirow[t]{2}{*}{ Source } & \multicolumn{3}{|l|}{2000} & \multicolumn{3}{|l|}{2010} \\
\hline & $C_{p 2000}$ & $C_{f 2000}$ & $C_{f 2000}-C_{p 2000}$ & $C_{p 2010}$ & $C_{f 2010}$ & $C_{f 2010}-C_{p 2010}$ \\
\hline \multicolumn{7}{|c|}{ Carbon emission per unit of energy consumption (tc/tce) } \\
\hline IPCC & 0.675 & 0.663 & -0.012 & 0.646 & 0.645 & -0.001 \\
\hline NDRC & 0.642 & 0.640 & -0.002 & 0.624 & 0.623 & -0.001 \\
\hline DEUS & 0.607 & 0.600 & -0.007 & 0.589 & 0.585 & -0.004 \\
\hline ORNL & 0.638 & 0.637 & -0.001 & 0.620 & 0.619 & -0.001 \\
\hline \multicolumn{7}{|c|}{ Carbon emission per unit of output (tc/10 4 yuan) } \\
\hline IPCC & 2.540 & 1.940 & -0.600 & 1.773 & 1.451 & -0.322 \\
\hline NDRC & 2.413 & 1.873 & -0.540 & 1.713 & 1.401 & -0.312 \\
\hline DEUS & 2.284 & 1.757 & -0.527 & 1.615 & 1.317 & -0.298 \\
\hline ORNL & 2.397 & 1.864 & -0.533 & 1.702 & 1.391 & -0.311 \\
\hline \multicolumn{7}{|c|}{ Per capita carbon emission (tc/per) } \\
\hline IPCC & 0.762 & 0.761 & -0.001 & 1.063 & 1.563 & 0.500 \\
\hline NDRC & 0.724 & 0.735 & 0.011 & 1.027 & 1.509 & 0.482 \\
\hline DEUS & 0.686 & 0.689 & 0.003 & 0.968 & 1.418 & 0.450 \\
\hline ORNL & 0.720 & 0.731 & 0.011 & 1.020 & 1.499 & 0.479 \\
\hline
\end{tabular}

Note: GDP values in 2000 and 2010 are converted into the constant price in 1990.

Table 9

Various decomposition factors and contribution rates for carbon emission changes (2010).

\begin{tabular}{lll}
\hline Factors & $\begin{array}{l}\text { Contribution rate } \\
(\%)\end{array}$ & $\begin{array}{l}\text { Carbon emission } \\
\left(10^{6} \mathrm{tc}\right)\end{array}$ \\
\hline $\begin{array}{l}\text { Population size effect }\left(\Delta C_{P}\right) \\
\begin{array}{l}\text { Economic development effect } \\
\left(\Delta C_{P G}\right)\end{array}\end{array}$ & $\begin{array}{l}-18.21 \\
\text { Intensity effect }\left(\Delta C_{t}\right)\end{array}$ & -106.26 \\
$\begin{array}{l}\text { Structure effect }\left(\Delta C_{S}\right) \\
\text { Total }\end{array}$ & -60.88 & 1048.62 \\
& 100 & -355.22 \\
& & -3.64 \\
\hline
\end{tabular}

is the greatest, followed by the energy intensity effect and the population size effect; the energy structure effect is the smallest (see Table 9). The economic development and population size effects are consistent with the previous EDS2050 failure, or the causes of EDS2050 failure continue to affect carbon emissions. Therefore, the following subsection focuses on the effects of energy consumption intensity and energy consumption structure on carbon emissions.

\subsection{Analysis of carbon emission intensity}

Carbon emissions per unit of output: according to the results in Table 9, failure of EDS2050 has a decreasing effect on carbon emissions per unit of output in China, which is mainly caused by technological advances in energy efficiency. Based on the real GDP in 2010 and three industrial structures for calculation, the decreased energy intensity values of three classes of industries (see Table 3 ) were 0.29 tce $/ 10^{4} \mathrm{RMB}, 0.46 \mathrm{tce} / 10^{4} \mathrm{RMB}$, and $0.27 \mathrm{tce} / 10^{4} \mathrm{RMB}$. Therefore, due to technological advances, $1194.25 \times 10^{6}$ tce of energy consumption was saved, which is equivalent to reducing emissions by $771.88 \times 10^{6}$ tc. In the same period, the proportion of primary industries dropped by $7.9 \%$, while those of second and tertiary industries respectively increased by $3.3 \%$ and $4.6 \%$ (see Table 2). Due to the changes in industrial structure, energy consumption increased by $408.88 \times 10^{6}$ tce, which is equivalent to an increase in emissions of $264.27 \times 10^{6}$ tc. The effect of technology advances on carbon emissions is greater than that of industrial structure; thus, the overall decline is shown in terms of carbon emissions per unit of output.

Per capita carbon emissions: The 2010 EDS2050 failure has increased the effect on Chinese per capita carbon emissions, which is mainly caused by two factors. First, the rural per capita carbon emissions are underestimated. The actual value of Chinese rural per capita energy consumption was $204 \mathrm{kgce}$ in 2010, which is higher than the predicted value by $66 \mathrm{kgce}$ (see Table 4). Based on the actual rural population of $6.71 \times 10^{8}$, this is equivalent to an extra $29.93 \times 10^{6}$ tc of emissions. Second, the urbanization rate is also underestimated. In 2000-2010, the Chinese urban population increased by $2.11 \times 10^{8}$, while the urban per capita living energy consumption was higher than that in the rural areas by 111 gce during the same period (see Table 4), which is equivalent to an extra $15.83 \times 10^{6}$ tc of emissions. The improvement in rural per capita carbon emissions is the main reason for the underestimation of Chinese per capita carbon emissions. In addition, urban per capita living energy consumption is still overestimated. In 2010 , the actual value of urban per capita living energy consumption was lower than the predicted value by $72 \mathrm{kgce}$. Based on the real urban population of $6.70 \times 10^{8}$ in 2010 (see Table 4), this is equivalent to emissions being reduced by $31.12 \times 10^{6}$ tc. However, the amount of overestimation is still less than the amount of underestimation, leading to an increased effect on per capita carbon emissions.

Carbon emissions per unit of energy consumption: Carbon emissions per unit of energy consumption are mainly affected by the energy consumption structure. According to our calculations, the contribution rate of energy consumption structure to carbon emissions in China is only $-0.62 \%$, which is because the predicted value of energy consumption structure in EDS2050 $\left(P_{2010}\right)$ is very close to the actual value $\left(A_{2010}\right)$ (see Table 1$)$. Based on energy consumption in 2010, due to the change in the structure of energy consumption, the energy consumption increased by more than $124.38 \times 10^{6}$ tce, which is equivalent to an extra $75.63 \times 10^{6}$ tc of emissions, accounting for only $3.6 \%$ of the total annual carbon emissions. It can be found that the effect of energy consumption structure on carbon emissions is very limited.

In summary, the impact of EDS2050 failure on carbon emissions has been analyzed from the increased effects on carbon 
emissions, and the underestimation of economic growth is still the factor with the greatest contribution. In addition, the impact of EDS2050 failure on carbon emissions has been analyzed from the perspective of the reduced effects on carbon emission intensity, in which technological progress plays a leading role.

\section{Policy implications}

Based on the above analysis, the main reason for EDS2050 failure is the underestimation of total energy due to the underestimation of sustained rapid economic growth, and maintained rapid urbanization. China has made great efforts toward curbing population growth, reducing energy consumption per unit of GDP through technological advances, and optimizing the energy consumption structure by increasing the proportion of clean energy, which has produced a better effect on carbon emissions. With future rapid development of industrialization and urbanization, China is facing ever-increasing energy and environmental pressures [34,35]. China is still in the middle stage of industrialization. In order to realize the target for GDP and per capita income in 2020 to double those in 2010, the process of industrialization will continue to increase. Even if the energy consumption intensity per unit of GDP is reduced, total production energy consumption will increase in the short term [36]. With improvement in the level of urbanization, living energy consumption will undergo a significant increase. According to previous calculation analysis, living energy consumption will grow to $4.42 \times 10^{8}$ tce in 2020 , which is an increase of $42.12 \%$ compared to 2010 [37].

Based on the targets of promoting economic development, conserving energy consumption, and reducing $\mathrm{CO}_{2}$ emissions, China's future sustainable energy strategy should highlight the following three points.

First, energy efficiency should be improved. This can be achieved by means of industrial restructuring and technological progress. With regard to industrial restructuring, the energy intensity of the Chinese secondary industries was 3.72 tce $/ 10^{4} \mathrm{RMB}$ in 2010 , and that of tertiary industries was 0.79 tce $/ 10^{4} \mathrm{RMB}$ (see Table 3 ). The energy consumption of secondary industries was 4.71 times that of tertiary industries. In the same period, China's three industrial structures had a ratio of 10/47/43 (primary/secondary/tertiary), while that of the USA was $1 / 20 / 79$ [38]. Having an industrial structure with a greater proportion of secondary industries and a smaller proportion of tertiary industries will lead to future industrial restructuring focusing on the development of modern services and high-technology industries, showing enormous potential to achieve energy conservation and carbon emission reduction targets by 2020 in China. From the perspective of technical progress, China's comparable energy consumptions per tonne of steel and cement were $668 \mathrm{kgce} / \mathrm{t}$ and $158 \mathrm{kgce} / \mathrm{t}$ in 2007, respectively, which were higher than the global advanced levels by $9.5 \%$ and $24.4 \%$ [39]. Therefore, the reductions in comprehensive energy consumption of steel, cement, and other industrial products through technological advances are of great significance for China to achieve its emission reduction targets by 2020 .

Second, energy use structure should be optimized. China remains a country that uses coal as one of its main energy. The proportion of coal use is higher than that of other countries by $40-$ $50 \%$, while the proportions of oil and gas use are lower than those of other countries by $40 \%$. China is rich in renewable energy, with its theoretical hydropower and wind power reserves being $6.94 \times$ $10^{8} \mathrm{~kW}$ and $20 \times 10^{8} \mathrm{~kW}$, respectively, and the domestic total annual solar radiation reaching $335-837 \mathrm{~kJ} / \mathrm{m}^{2}$ a. China has one of the world's most abundant renewable energy[40]. However, as viewed from the perspective of the utilization rate of renewable energy, the proportion of renewable energy power and nuclear power in the national total energy consumption in China accounted for only $8.6 \%$ in 2010 , which is far below the average level of developed countries. The core of China's future sustainable energy strategy is to gradually reduce the proportion of coal use, and improve the proportion of renewable energy use. According to China's Long-term Renewable Energy Development Plan, China's renewable energy consumption will account for $15 \%$ of the national total by 2020, and its development and utilization amount will be $6 \times 10^{8}$ tce, which is equivalent to a reduction of emissions of $12 \times 10^{8}$ tc [41]. Therefore, China should accelerate the development of its western energy-rich regions, and promote the development of hydropower, solar energy, and other important resources.

Third, universal energy conservation should be promoted. Although Chinese per capita energy consumption only accounts for about $20 \%$ of that of the USA and other developed countries, the potential for energy conservation and emission reduction is still extremely large. Based on research into quantitative indicators of national potential for energy conservation and emission reduction carried out by domestic experts, the annual conserved energy of 36 universal daily living activities is approximately $77 \times 10^{6}$ tce, which is equivalent to a reduction in emissions of $0.5 \times 10^{8}$ tc. The accumulated conserved energy consumption in 2005-2020 will be $11.6 \times 10^{6}$ tce, which is equivalent to a reduction of $3.2 \times 10^{8}$ tc [42]. In addition, during the active promotion of the urbanization process, the Chinese government should encourage the development of public transportation and alternative energy vehicles, reduce the proportion of car trips, strictly control the per capita housing area of urban and rural residents, and vigorously pursue the use of green building materials and energy-saving, environmentally friendly materials.

\section{Acknowledgments}

We are grateful to the anonymous reviewers for their useful comments and suggestions that have improved the manuscript. We also would like to acknowledge the funding of Key Research Program of the Chinese Academy of Sciences (KZZD-EW-06), Advanced Programs of Science and Technology Service Network Initiative of Chinese Academy of Sciences (KEJ-EW-ZY-004).

\section{References}

[1] Tien MD, Deepak S. Vietnam's energy sector: a review of current energy policies and strategies. Energy Policy 2011;39:5770-7.

[2] John AM, Erik SR. Renewables, manufacturing and green growth: energy strategies based on capturing increasing returns. Future 2014;61:13-22.

[3] Hui MW, Wen HY, Chao WC, Marivic VP. Renewable energy supply chains, performance, application barriers, and strategies for further development. Renew Sustain Energy Rev 2012;16:5451-65.

[4] Alaa A, David K, Stefan W, Thomas V. Moroccan National Energy Strategy reviewed from a meteorological perspective. Energy Strategy Rev 2015;6:39-47.

[5] Nor AB, Ahmad TR, Abubakar SA. Malaysia energy strategy towards sustainability: a panoramic overview of the benefits and challenges. Renew Sustain Energy Rev 2015;42:1094-105.

[6] da Graca Carvalho M. EU energy and climate change strategy. Energy 2012;40:19-22.

[7] Sudhakara Reddy B, Hippu SKN. Energy in the development strategy of Indian households: the missing half. Renew Sustain Energy Rev 2013;18:203-10.

[8] Farshid S, Paras M, Anurag KS. Demand response for sustainable energy systems: a review, application and implementation strategy. Renew Sustain Energy Rev 2015;45:343-50.

[9] Benjamin CM, Oi Z, Agya Utama N, Hooman F, Keiichi NI. Analysis of Japan's post-Fukushima energy strategy. Energy Strategy Rev 2013;2:190-8.

[10] Lo K. A critical review of China's rapidly developing renewable energy and energy efficiency policies. Renew Sustain Energy Rev 2014;29:508-16.

[11] Menegaki AN. On energy consumption and GDP studies: a meta-analysis of the last two decades. Renew Sustain Energy Rev 2014;29:31-6.

[12] Wang SJ, Fang CL, Guan XL, Pang B, Ma HT. Urbanization, energy consumption, and carbon dioxide emissions in China: a panel data analysis of China's provinces. Appl Energy 2014;136:738-49. 
[13] Ermis K, Midilli A, Dincer I, Rosen MA. Artificial neural network analysis of world green energy use. Energy Policy 2007;35:1731-43.

[14] Ekonomou L. Greek long-term energy consumption prediction using artificial neural networks. Energy 2010;35:512-7.

[15] Ünler A. Improvement of energy demand forecasts using swarm intelligence: the case of Turkey with projections to 2025. Energy Policy 2008;36:1937-44.

[16] Azadeh A, Saberio M, Seraj O. An integrated fuzzy regression algorithm for energy consumption estimation with non-stationary data: a case study of Iran. Energy 2010;35:2351-66.

[17] Shi J, Guo J, Zheng S. Evaluation of hybrid forecasting approaches for wind speed and power generation time series. Renew Sustain Energy Rev 2012;16:3471-80.

[18] Shabbir R, Ahmad SS. Monitoring urban transport air pollution and energy demand in Rawalpindi and Islamabad using leap model. Energy 2010;35:2323-32.

[19] Ediger VŞ, Akar S. ARIMA forecasting of primary energy demand by fuel in Turkey. Energy Policy 2007;35:1701-8.

[20] Lee YS, Tong LI. Forecasting nonlinear time series of energy consumption using a hybrid dynamic model. Appl Energy 2012;94:251-6.

[21] Crompton P, Wu Y. Energy consumption in China: past trends and future directions. Energy Econ 2005;27:195-208.

[22] Wang R, Liu WJ, Xiao LS, Liu J, Kao W. Path towards achieving of China's 2020 carbon emission reduction target-a discussion of low-carbon energy policies at province level. Energy Policy 2011;39:2740-7.

[23] Pao $\mathrm{HT}$, Fu HC, Tseng CL. Forecasting of $\mathrm{CO}_{2}$ emissions, energy consumption and economic growth in China using an improved grey model. Energy 2012:40:400-9.

[24] Chandarasekharam D, Lashin $\mathrm{A}, \mathrm{Al} \mathrm{AN} . \mathrm{CO}_{2}$ mitigation strategy through geothermal energy, Saudi Arabia. Renew Sustain Energy Rev 2014;38:154-63.

[25] Yan FD, Jiu PX, Ying L, Karen M. Biogas as a sustainable energy source in China: regional development strategy application and decision making. Renew Sustain Energy Rev 2014;35:294-303.

[26] Office of the NPC Financial and Economic Committee. Development and Planning Department of National Development and Reform Commission. Five-year plans for national economic and social development since the founding of the People's Republic of China. Beijing: China's Democracy and Law Press; 2008.

[27] Xu JH. Quantity geography. Beijing: Higher Education Press; 2006.
[28] Lo KA. Critical review of China's rapidly developing renewable energy and energy efficiency policies. Renew Sustain Energy Rev 2014;29:508-16.

[29] Chang J, Leung DYC, Wu CZ, Yuan ZH. A review on the energy production, consumption, and prospect of renewable energy in China. Renew Sustain Energy Rev 2003;17:453-68.

[30] Wang Q. Effects of urbanization on energy consumption in China. Energy Policy 2014;65:332-9.

[31] IPCC. IPCC guidelines for national greenhouse gas inventories. Japan: IGES 2006. p. 450.

[32] Ang BW. The LMDI approach to decomposition analysis: a practical guide. Energy Policy 2005;33:867-71.

[33] Wang CJ, Zhang L, Wang Q, Qiao Y. Analysis of dynamic evolution of energyrelated $\mathrm{CO}_{2}$ emission in Shandong province. J Graduate Univ Chin Acad Sci 2012;29:469-75.

[34] Ding ZL, Duan XN, Ge QS, Zhang ZQ. Control of atmospheric $\mathrm{CO}_{2}$ concentration by 2050: an allocation on the emission rights of different countries. Sci China Ser D: Earth Sci 2009;39:1009-27.

[35] Ge QS, Fang XQ. Analysis of the factors and countermeasures for scientifically coping with climate change. Bull Chin Acad Sci 2010;25:32-40.

[36] Liu H, Fan J, Guillaume G. Carbon emission trend and green economy prospect in China. China Popul Resour Environ 2011;21:151-4.

[37] Fan J, Li PX. Analysis on the future energy consumption and preliminary discussion on carbon emission of China from the perspective of urbanization. Adv Earth Sci 2011;26:57-65.

[38] World Bank. World development indicators. 〈http://www.worldbank.org data/ $>2014$.

[39] Liu YH, Ge OS, He FN, Cheng BB. Countermeasures against international pressure of reducing $\mathrm{CO}_{2}$ emissions and analysis on China's potential of $\mathrm{CO}_{2}$ emission reduction. Acta Geogr Sin 2008;63:675-82.

40] Chao B, Chuang-lin F. Geographical and environmental perspectives for the sustainable development of renewable energy in urbanizing China. Renew Sustain Energy Rev 2013;27:464-74.

41] National Development and Reform Commission. Middle and long term programme of renewable energy development. 〈http://www.sdpc.gov.cn/〉; 2007.

[42] Department of Social Development of Ministry of Science and Technology of the PRC, Administrative Centre for China's Agenda 21. Practical civil booklet for energy saving and emission reduction. Beijing: Social Sciences Academic Press; 2007 